\title{
Um Modelo para Promover o Engajamento Estudantil no Aprendizado de Programação Utilizando Gamification
}

\section{A Model to Promote Student Engagement in Programming Learning Using Gamification}

\author{
Tatyane Souza Calixto da Silva \\ Centro de Informática - \\ Universidade Federal de \\ Pernambuco (UFPE) \\ tscs@cin.ufpe.br
}

\author{
Jeane Cecília Bezerra de Melo \\ Departamento de Estatística e \\ Informática - Universidade Federal \\ Rural de Pernambuco (UFRPE) \\ jeane.ufrpe@gmail.com
}

\author{
Patricia Cabral de Azevedo Restelli \\ Tedesco \\ Centro de Informática - Universidade \\ Federal de Pernambuco (UFPE) \\ pcart@cin.ufpe.br
}

\begin{abstract}
Resumo
O aprendizado de programação apresenta desafios e dificuldades em diferentes níveis, podendo ocasionar baixo desempenho e desmotivação no estudante, aumentando o índice de evasão em cursos de Computação e Informática. As metodologias tradicionais de ensino, por sua vez, não têm apresentado resultados satisfatórios para amenizar tais dificuldades. Neste estudo, utilizamos o engajamento estudantil, concomitantemente às técnicas de gamification, como forma de minimizar os problemas acima citados. Nesse contexto, a pesquisa aqui apresentada busca investigar a influência da utilização de um modelo gamificado para promover o engajamento estudantil e auxiliar o aprendizado de programação, para proporcionar um aprendizado personalizado. Com esse intuito, um modelo foi elaborado, baseando-se no perfil de jogadores e técnicas de engajamento de games. Para mensurarmos a influência deste modelo, o mesmo foi implementado através da ferramenta intitulada cod[edu]. Os resultados obtidos mostraram que houve aumento nos valores dos indicadores de engajamento, sinalizando uma influência positiva neste aspecto, devido ao uso do modelo proposto. A conclusão da pesquisa apresenta recomendações e estratégias de aprendizagem consideradas significativas para amenizar o problema, além da proposta de trabalhos futuros.
\end{abstract}

Palavras-Chave: Engajamento Estudantil; Aprendizagem de Programação; Gamification; Tecnologia Educacional.

\begin{abstract}
Learning to program presents challenges and difficulties at different levels, which may cause student's low performance and lack of motivation, which increase dropout rates in Computing and Information Technology courses. Traditional teaching methods, in turn, have not shown satisfactory results to ease such difficulties. In this study, we used the student engagement together with gamification techniques, in order to minimize the problems mentioned above. In this context, the research presented here aims to investigate the influence of using a model with gamification to promote student engagement and help them to learn programming through a personalized learning experience. To that end, a model was developed, based on the profile of players and gaming engagement techniques. Measure to the influence of this model, a computational tool, entitled cod[edu]was implemented. The results showed that there was an increase in the values of engagement indicators, signaling a positive influence in this respect due to the use of the proposed model. The conclusion of the research presents recommendations and learning strategies considered significant to ease the problem, beyond the proposal of future work.
\end{abstract}

Keywords: Student Engagemen; Programming Learning; Gamification; Educational Technology.

Cite as: Silva, T. S.C., Melo, J. C.B. \& Tedesco, P.C. A. R. (2018). A Model to Promote Student Engagement in Programming Learning Using Gamification (Um Modelo para Promover o Engajamento Estudantil no Aprendizado de Programação Utilizando Gamification). Brazilian Journal of Computers in Education (Revista Brasileira de Informática na Educação - RBIE), 26(3), 120-138. DOI: 10.5753/RBIE.2018.26.03.120 


\section{Introdução}

O Currículo de Referência da Sociedade Brasileira de Computação aponta que a disciplina de programação é essencial para formação sólida dos discentes de diversos cursos de Computação (Sociedade Brasileira de Computação [SBC], 1999). Embora a disciplina de programação seja considerada fundamental na formação acadêmica dos discentes, estudos indicam que o seu aprendizado não é trivial (Giraffa, Muller \& Moraes, 2015). As dificuldades enfrentadas pelos alunos no aprendizado de programação citadas com maior frequência na literatura são: baixa compreensão das noções básicas, como estrutura de controle; criação de algoritmos que resolvam problemas concretos; aprender a pensar algoritmicamente; uma base matemática fraca; uso de linguagens de programação com sintaxes rebuscadas para estudantes em início de curso; o não entendimento dos enunciados; exercícios dissociados de problemas "reais" e pouca disponibilidade extraclasse para estudos (Gomes \& Mendes, 2014; Yang, Yang, \& Hwang, 2014).

Esses fatores sofrem a influência da experiência anterior dos alunos iniciantes que, em sua maioria, vêm de um sistema educacional fundamentado na memorização/reprodução de informações e mecanização de procedimentos. Além disso, é comum a utilização de metodologia tradicional para o ensino de programação, (Gomes \& Mendes, 2014), que costuma dividir as aulas em teóricas, teóricas-práticas e/ou laboratoriais, no entanto não tem se mostrado adequada ao ensino desta disciplina (Gomes \& Mendes, 2014).

Essas dificuldades causam, inevitavelmente, elevadas taxas de insucesso ou desistência dos estudantes de cursos de Computação (Gomes \& Mendes, 2014). Segundo o Instituto Nacional de Estudos e Pesquisas Educacionais Anísio Teixeira (INEP, 2012) o índice de evasão dos cursos das áreas exatas é de $28 \%$. Esse valor é considerado alto, uma vez que a média nacional é de $23 \%$. Ao analisar a área de Computação, observa-se que a disciplina de programação é apontada como responsável, ou contribui de maneira efetiva, pela evasão e reprovação nos primeiros períodos do curso (Costa \& Giraffa, 2013).

Uma das implicações desse panorama é a desmotivação do estudante com a área de programação, refletindo no atraso do curso (Brito \& Madeira, 2015). Diante dessa situação, é necessário buscar maneiras de propor soluções que possam tratar essa condição de forma efetiva (Brito \& Madeira, 2015).

Os professores, por sua vez, enfrentam o desafio de ensinar em turmas grandes, que inviabiliza a realização de um acompanhamento individualizado, e heterogêneas, que apresentam disparidade de conhecimento e ritmo de aprendizagem (Lahtinen, Ala-Mutka, \& Järvinen, 2014). Apesar dessas dificuldades, diferentes estilos e metodologias podem ajudar a motivar os discentes.

Uma das formas utilizadas com o intuito de motivar, engajar e influenciar positivamente na mudança do comportamento de um público definido por intermédio da utilização de elementos de jogos é conhecida como gamification (Deterding, Dixon, Khaled, \& Nacke, 2011). Nesse contexto, o uso de gamification possibilita resultados melhores do que os alcançados por métodos tradicionais de ensino (Brazil \& Baruque, 2015), o qual pode ser definido como a utilização de várias técnicas e elementos de games em contextos não orientados a jogos, com o intuito de motivar e engajar indivíduos a resolver vários problemas (Brazil \& Baruque, 2015). A finalidade de gamification é transformar atividades reais em tarefas mais divertidas e lúdicas, e assim, promover e manter a motivação e engajamento dos indivíduos no cumprimento dessas atividades (Peixoto, Silva, Vilela, \& Gonçalves, 2015).

Com o intuito de tornar o processo de aprendizagem mais dinâmico, pode-se buscar personalizar o aprendizado, tornando-o mais eficiente. Um conceito que pode contribuir para 
isto é o Contexto Computacional, definido como qualquer informação que caracteriza a situação de uma entidade (pessoa, lugar ou objeto) considerado relevante para a interação entre uma pessoa e uma aplicação. Sistemas Sensíveis ao Contexto são aqueles onde há gerenciamento de informações contextuais relacionados a uma aplicação com o intuito de apoiar um agente na execução de uma atividade (Vieira, Tedesco \& Salgado, 2009).

Diante desse cenário, esta pesquisa visa investigar a influência positiva de gamification no engajamento e desempenho dos estudantes no aprendizado de programação. Para tanto, um modelo conceitual foi definido, o qual utiliza gamification, baseando-se no perfil de jogadores e técnicas de engajamento para proporcionar um aprendizado personalizado e promover o engajamento estudantil.

Este artigo está organizado como segue: na seção 2 são apresentados os conceitos de engajamento estudantil. A seção 3 aborda a definição de jogo, perfil de jogadores e gamification. A seção 4 apresenta os trabalhos relacionados. A seção 5 aborda o modelo conceitual. A seção 6 apresenta o estudo experimental. Por fim, na seção 7 são feitas as considerações finais da pesquisa, destacando as contribuições do estudo e apontando algumas direções para trabalhos futuros.

\section{Engajamento Estudantil}

A literatura apresenta diversas definições sobre engajamento não havendo, no entanto, um consenso sobre o seu conceito (Atweh, Bland, Carrington, \& Cavanagh, 2007; Fredricks, Blumenfeld, \& Paris, 2004; Parsons \& Taylor, 2011). As divergências nas definições, para Parsons \& Taylor (2011), repercute no problema de definir em qual nível está o engajamento do aluno.

\subsection{Tipos de Engajamento}

Com o intuito de entender o conceito em si, surgiram diversas recomendações para categorizar os tipos e/ou aspectos de engajamento, por exemplo: comportamental, cognitivo e emocional (Parsons \& Taylor, 2011).

\subsubsection{Engajamento Comportamental}

O engajamento comportamental está relacionado com a colaboração e envolvimento do discente nas atividades curriculares e é principalmente avaliado quantitativamente, baseando-se em aspectos tais como: frequência, eficácia e tempo empregado na realização de tarefas (Fredricks et al., 2004; Viter, 2013).

\subsubsection{Engajamento Cognitivo}

O engajamento cognitivo inclui o envolvimento psicológico do discente no processo de aprendizagem. Esse tipo de engajamento estimula habilidades cognitivas complexas como a competência de analisar, confrontar e examinar, que são usadas com o intuito de desenvolver a própria compreensão, resolver problemas complexos e construir novos conhecimentos (Fredricks et al., 2004).

\subsubsection{Engajamento Emocional}

Esse tipo de engajamento envolve comportamentos afetivos e emocionais dos alunos diante de tarefas, de outros indivíduos e de elementos que estruturam o ambiente educacional. Alguns exemplos desses comportamentos são: ansiedade, tédio, frustração, felicidade e interesse (Fredricks et al., 2004; Seixas, Melo, \& Gomes, 2015). 


\subsection{Indicadores de Engajamento}

A literatura traz indicadores ou variáveis de engajamento com a finalidade de analisar se ocorreu alguma modificação no contexto de suas intervenções. No entanto, não há uma padronização desses indicadores que venha a identificar o engajamento dos estudantes (Parsons \& Taylor, 2011). O engajamento pode ser reconhecido através da Autonomia, Execução, Social, Entrega, Participação, Colaboração, Cooperação, Questionamento e Diversão do estudante ao realizar uma atividade (Parsons \& Taylor, 2011; Russell \& Slater, 2010).

Para uma melhor compreensão dos conceitos e inter-relações aqui abordados, os indicadores de engajamento foram resumidos na Tabela 1 (Seixas, Melo, \& Gomes, 2015).

Tabela 1: Indicadores de engajamento comportamental encontrados na literatura.

\begin{tabular}{|c|c|}
\hline Indicadores & Descrição \\
\hline Autonomia & $\begin{array}{l}\text { Corresponde à capacidade do aluno em estudar em casa de forma autônoma e tomar decisões } \\
\text { sem a intervenção contínua do professor. }\end{array}$ \\
\hline Execução & Identificado quando o aluno realiza as atividades propostas pelo professor em sala de aula. \\
\hline Social & Atribuído quando o aluno tem um bom relacionamento com os colegas e o professor. \\
\hline Entrega & $\begin{array}{l}\text { O aluno não apenas realiza as atividades, mas essas ocorrem sempre nos prazos } \\
\text { estabelecidos pelo professor. }\end{array}$ \\
\hline Participação & $\begin{array}{l}\text { Durante a realização de discussões em sala de aula ou explanação do conteúdo, o aluno } \\
\text { sempre contribui. }\end{array}$ \\
\hline Colaboração & $\begin{array}{l}\text { O aluno tem a atitude de ajudar os demais colegas da sala de aula, mesmo não sendo um } \\
\text { trabalho em equipe. }\end{array}$ \\
\hline Cooperação & $\begin{array}{l}\text { Durante a realização de trabalhos em equipe, o aluno tem iniciativa e contribui com seu } \\
\text { grupo. }\end{array}$ \\
\hline Questionamento & $\begin{array}{l}\text { O aluno não se sente intimidado ou constrangido em questionar o professor sobre os } \\
\text { conteúdos estudados. }\end{array}$ \\
\hline Diversão & O aluno realiza as atividades não apenas pela obrigação, mas por considerar essas divertidas. \\
\hline
\end{tabular}

\section{Perfil de Jogadores, Técnicas de Engajamento e Gamification}

Concomitantemente à identificação do tipo de engajamento através de seus indicadores, se faz necessário estabelecer o perfil dos jogadores, proporcionando assim critérios de seleção de métodos que promovam o ensino de programação.

\subsection{Perfis dos Jogadores e Técnicas de Engajamento}

Segundo Ghozland (2010) a relevância da experiência de um jogo para um jogador é resultado da motivação que o game pode gerar. Nessa perspectiva, os autores Zichermann e Cunningham (2011) afirmam que para se projetar uma experiência ou guiar um comportamento de forma desejada é necessário compreender o comportamento do indivíduo dentro do contexto de jogo. Uma forma de identificar o jogador, baseando-se em seu comportamento e as diversas formas de serem motivados, é recomendada por Bartle (1996). Esse autor publicou um estudo onde propõe uma taxonomia para entender como os diversos perfis de jogadores são motivados e os classificou em quatro categorias: predadores, conquistadores ou realizadores, comunicadores ou socializadores e exploradores.

Os jogadores que têm o perfil de predador compõem a menor porcentagem de tipos de jogadores (Zichermann \& Cunningham, 2011). Os predadores têm o interesse de mostrar o quanto são superiores a outros jogadores, que são vistos como seus inimigos, e não têm interesse em interação social (Bartle, 1996). Os jogadores que têm o perfil predador interagem com outros jogadores de maneira intensa e competitiva (Alves, 2014). 
Os jogadores classificados como conquistadores (Alves, 2014), também chamados de realizadores (Sena \& Coelho, 2012), são motivados através do cumprimento das missões, quests, recompensas, pontos, e orgulham-se de sua posição na hierarquia do jogo, bem como, do pouco tempo usado para alcançá-la (Bartle, 1996).

Os exploradores, por sua vez, estão em busca das premissas que mobilizam o jogo. $\mathrm{O}$ jogador que possui esse perfil tem o intuito de descobrir ao máximo a mecânica do ambiente do jogo e seus desafios (Zichermann \& Cunningham, 2011).

Por fim, os jogadores comunicadores ou socializadores, ocupam uma posição que comprova a interação desses com outros jogadores. Indivíduos que possuem esse perfil de jogador utilizam o game como um meio para interagir com outras pessoas, fazer amizades e disseminar sua influência (Bartle, 1996).

Uma outra forma de motivar os jogadores, de acordo com seu perfil, se dá através das técnicas de engajamento (Sena \& Coelho, 2012; Zichermann \& Cunningham, 2011), apresentadas a seguir: Desafios e Missões: dar aos jogadores direção para o que fazer dentro do ambiente do jogo por intermédio da experiência do jogo. Achievements ou Badges: recompensas dadas aos jogadores após alcançar uma conquista ou cumprir uma tarefa. Progress Bar: tem o intuito de mostrar ao jogador a sua evolução ao longo do jogo. Rankings e Leader Board: aumenta a motivação dos jogadores através da competição entre eles.

\subsection{Gamification}

Entende-se que o conceito de gamification sustenta-se em pensar e agir como em um jogo, usando para isso as mecânicas e dinâmicas de games em um contexto fora do jogo. Zichermann (2011) afirma que "gamification consiste no processo de utilização de pensamento de jogos e dinâmicas de jogos para engajar audiências e resolver problemas". Outro conceito de gamification que complementa o de Zichermann (2011) é que o gamification usa mecanismos de jogos para resolver problemas, motivar e engajar um determinado público (Vianna et al., 2013).

Segundo Kapp (2012), gamification na educação consiste na utilização de elementos dos games fora do contexto dos jogos, com a finalidade de motivar os indivíduos à ação, auxiliar na solução de problemas e promover aprendizagem. No presente trabalho propõe-se a utilização de gamification considerando o perfil de jogadores e as técnicas de engajamento mais adequadas para estes, de modo a promover o ensino de programação.

\section{Trabalhos Relacionados}

Nesta seção são apresentadas ferramentas educacionais que utilizam gamification voltadas para o ensino de programação. 


\subsection{Codecademy}

Codecademy (2015)é uma plataforma e-learning para o aprendizado de programação, projetada com gamification. Nela, os cursos de programação são organizados em seções, constituídas por sequências de exercícios, que possuem um texto educativo para introduzir o tema, bem como instruções que indicam ao estudante o que fazer e o exercício interativo real para conclusão dessa atividade. Os alunos são recompensados com badges quando atingem determinado número de pontos, ou de certas aulas ou cursos, que eles compartilham no Facebook. Nessa plataforma o professor não tem a possibilidade de acompanhar o progresso do estudante. $\mathrm{O}$ sistema não é sensível ao contexto e não se adequa a interação do usuário com o sistema, para auxiliar no aprendizado do estudante.

\subsection{Plataforma OREY Gamification}

A plataforma proposta apoia o ensino de programação em e-learning e fornece funcionalidades centrais do LMS (Learning Management Systems), permitindo aos docentes o compartilhamento de materiais de aprendizagem para os alunos, acompanhamento do progresso dos estudantes e a comunicação com os alunos e seus grupos (Swacha \& Baszuro, 2013).

A plataforma é gamificada e utiliza alguns elementos de jogos, tais como: progress bar, achievements e leardboard. $\mathrm{O}$ ambiente permite submissões dos exercícios que podem ser avaliadas tanto automaticamente (em termos de exatidão e eficiência) ou pelo professor, em termos de qualidade (Swacha \& Baszuro, 2013).

Essa proposta de plataforma para o ensino de programação não é sensível ao contexto, nem efetua verificação automática sobre uma verificação automática sobre quais exercícios os estudantes estão cometendo mais erros.

\subsection{PeerSpace}

O PeerSapce é um ambiente de aprendizagem com adição de recursos gamification baseado em rede social para incentivar a aprendizagem colaborativa dos alunos. Os recursos de aprendizagem relacionados incluem: a revisão por pares e feedbacks. O sistema atribui pontos aos alunos mediante participação nas atividades e número de iteração com as pessoas. Outro elemento utilizado com esta mesma finalidade é o leaderboard (Li, Dong, Untch, Chasteen, \& Reale, 2011).

O PeerSapce não é sensível ao contexto e não oferece ao docente a possibilidade de acompanhar, através de relatórios o andamento do aluno no ambiente. O sistema verifica apenas a quantidade de iterações entre os usuários, podendo pontuar os alunos que interagem mais vezes em detrimento daqueles que possuem uma rede maior de amigos.

\subsection{Codeschool}

O Codeschool (2015) é uma plataforma online para o ensino de programação. Os cursos são em forma de vídeos seguidos de exercícios, chamados de desafios. Utiliza elementos de jogos, tais como pontuação para cada desafio cumprido e badges quando o usuário passa de um nível a outro. O Codeschool não possibilita o acompanhamento do professor ao estudante. Como também, não apresenta a possibilidade de personalizar o aprendizado levando em consideração o perfil de jogador do aluno.

Com base no estudo relacionado, buscando identificar pontos fortes e fracos nas ferramentas disponíveis atualmente bem como, considerar os perfis de jogadores, técnicas de engajamento e gamification, o modelo cod[edu]foi desenvolvido, sendo apresentado a seguir. 


\section{Modelo Conceitual cod[edu]}

O modelo conceitual cod[edu] tem o intuito de promover o engajamento estudantil e auxiliar o desenvolvimento das habilidades e competências necessárias para a aprendizagem de programação (Figura 1).

O modelo conceitual é dividido em três partes: perfil de jogadores, as técnicas de engajamento e elementos de games. Os dois primeiros possuem o intuito de promover e manter o engajamento dos estudantes no ambiente de maneira contextualizada, sendo as técnicas de engajamento baseadas no perfil do jogador, as quais são escolhidas de modo a tornar a experiência mais significativa. As recomendações do sistema são baseadas e adaptadas ao estilo de cada jogador.

No que se refere aos elementos de games o modelo contempla: pontuação, narrativa e feedback, relacionando-os com as técnicas de engajamento. Em relação à competição, esta é promovida através da técnica de ranking e leaderboard. Por fim, as recompensas são associadas aos achievement ou badges usados com intuito de premiar cada tarefa finalizada.

O modelo conceitual contempla a taxonomia de Bloom ou Taxonomia dos Objetivos Educacionais proposta por Bloom, Engelhart e Furst (1956), cujo intuito é auxiliar no planejamento, organização e controle dos objetivos de aprendizagem. A taxonomia de Bloom é utilizada em várias áreas do conhecimento, sendo comprovada, inclusive, sua aplicabilidade na elaboração de instrumentos de avaliação na disciplina de programação (Whalley et al., 2006).

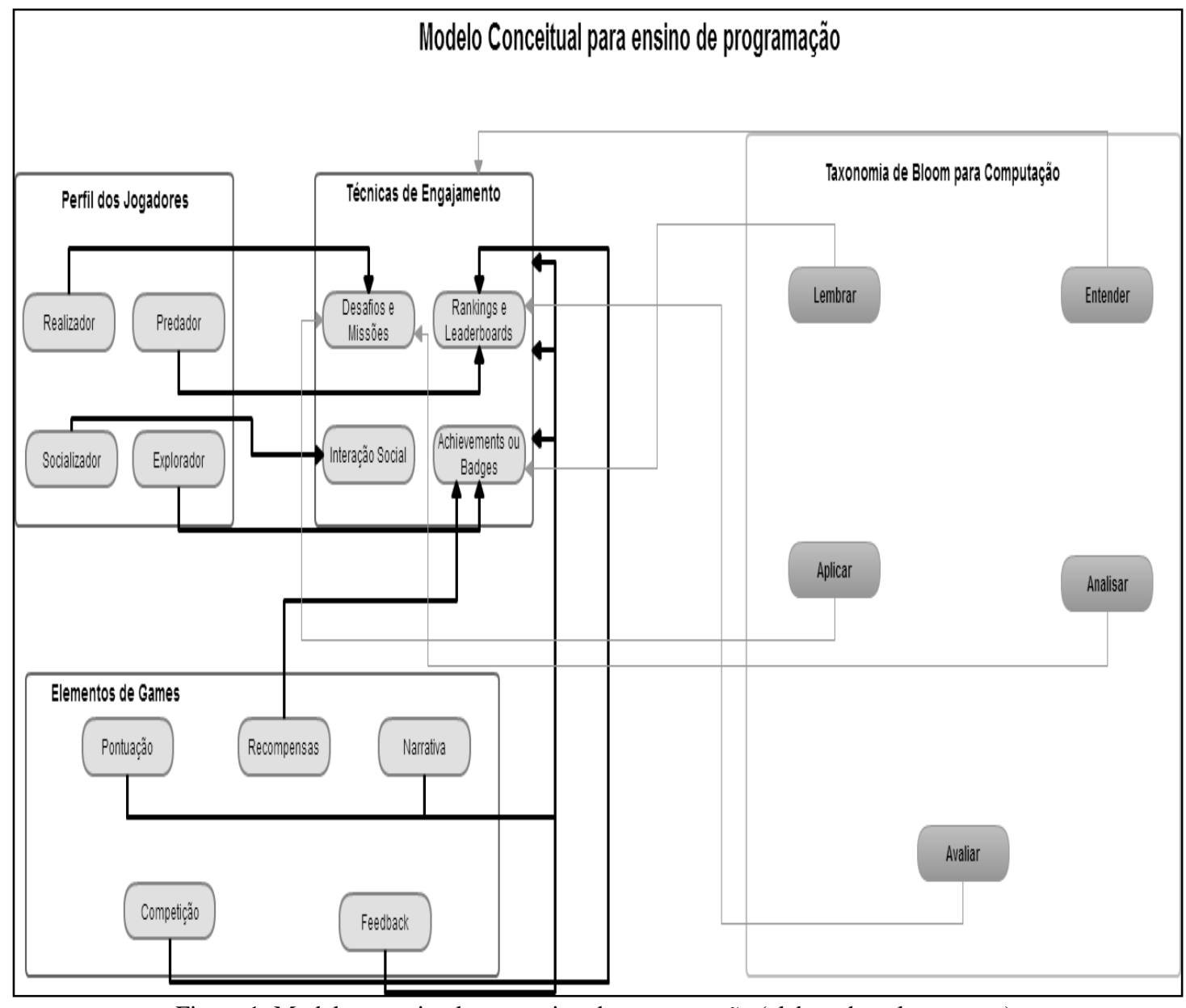

Figura 1: Modelo conceitual para ensino de programação (elaborado pelas autoras).

No contexto do modelo conceitual, a taxonomia de Bloom foi associada às técnicas de engajamento, para avaliar os objetivos educacionais, desempenho e envolvimento dos 
estudantes durante o seu processo de aprendizagem de programação, usando gamification. A seguir serão apresentadas as categorias da taxonomia de Bloom que o modelo conceitual contempla:

- Lembrar: essa categoria requer que o aluno resgate informações e/ou conhecimento da memória, por exemplo: No modelo conceitual ela está relacionada com achievement ou badges que são utilizados como recompensas, com o intuito de promover o engajamento discente e a aprendizagem, uma vez que é exigido do estudante o conhecimento para receber as recompensas por intermédio de exercícios em forma de quiz (Scott, 2003).

- Entender: essa categoria aborda a capacidade do estudante de dar um significado e interpretar o conhecimento adquirido através das experiências educacionais. (Krathwohl, 2002). No contexto do modelo conceitual, essa categoria está relacionada com todas as técnicas de engajamento, pois estas fornecem um feedback rápido, claro e relevante das interações dos estudantes, possibilitando ao estudante entender como um determinado conceito é aplicado de diferentes formas.

- Aplicar: categoria associada à execução ou utilização de um procedimento numa situação específica ou nova (Jesus \& Raabe, 2009). No âmbito do modelo condicional, relaciona-se com os desafios e missões, pois possibilita ao estudante aplicar o seu conhecimento para cumpri-los.

- Analisar: essa categoria contempla a capacidade do estudante de diferenciar, baseando-se no conhecimento adquirido, a informação relevante e compreender a inter-relação existente entre as partes (Jesus \& Raabe, 2009). No modelo conceitual, essa categoria está relacionada com desafios e missões por possibilitar a resolução de problemas e enigmas através da escolha de elementos distintos.

- Avaliar: essa categoria aborda a capacidade que o estudante tem de julgar critérios e padrões quantitativos e/ou qualitativos (Scott, 2003). No modelo conceitual, essa categoria está relacionada com ranking e leaderboard, uma vez que são técnicas de engajamento que são modificadas pela interação do jogador mostrando seu desempenho.

\subsection{Requisitos do Cod[edu]}

O processo de desenvolvimento de software é caracterizado por um conjunto de passos parcialmente organizados, formados por atividades, métodos, práticas e transformações, utilizados para alcançar um objetivo (Pádua, 2001). Nesse contexto, pode-se afirmar que o desenvolvimento de qualquer software fundamenta-se no levantamento de análise das necessidades dos futuros usuários (Tarallo, Rozenfeld, \& Barbalho, 2003).

Para este estudo, foi realizada uma pesquisa com alguns ambientes educacionais com o intuito de obter características dessas plataformas que usam gamification para o ensino de programação. Os requisitos de cada ambiente são detalhados a seguir: disponibilizar conteúdo didático, disponibilizar exercícios sobre o assunto abordado, facilitar a pesquisa de um conteúdo específico do curso, interface amigável e estrutura de fácil uso, realizar o acompanhamento do progresso do aluno, fornecer meios/canais para comunicação/ discussão entre os usuário, utilizar gamification e usar personalização da aprendizagem.

No que se refere ao sistema cod[edu], este utiliza a Recomendação baseada em Conteúdo (Vieira \& Nunes, 2012), uma vez que usa as interações do usuário, para classificar seu perfil de jogador e lançar técnicas de engajamento, baseando em seu perfil. Uma das principais vantagens desta técnica é que ela não necessita da avaliação prévia de um item para gerar a recomendação, possibilitando ainda que todos os itens serem recomendados, uma vez que dependem unicamente do perfil do usuário.

Após o levantamento dos requisitos, foi elaborado um quadro comparativo (Tabela 2) com os requisitos das ferramentas detalhadas na seção 4 e o ambiente cod[edu]. Ao observar o 
quadro comparativo pode-se perceber que o diferencial da ferramenta cod[edu]é permitir o acompanhamento do progresso do estudante e proporcionar a personalização do ensino por intermédio da recomendação.

Tabela 2: Quadro comparativo das ferramentas que usam gamification para o ensino de programação (elaborada pelas autoras).

\begin{tabular}{|c|c|c|c|c|c|}
\hline \multirow[b]{2}{*}{ Requisitos } & \multicolumn{5}{|c|}{ Ferramentas } \\
\hline & Codecademy & $\begin{array}{l}\text { Plataforma } \\
\text { OREY } \\
\text { Gamification }\end{array}$ & PeerSpace & CodeSchool & Codedu \\
\hline $\begin{array}{l}\text { Disponibilizar conteúdo } \\
\text { didático }\end{array}$ & $y$ & $\checkmark$ & & $\checkmark$ & \\
\hline $\begin{array}{l}\text { Disponibilizar exercícios sobre } \\
\text { o assunto abordado }\end{array}$ & $y$ & $\checkmark$ & & $\checkmark$ & \\
\hline $\begin{array}{l}\text { Facilidade para se encontrar um } \\
\text { conteúdo específico do curso }\end{array}$ & $\checkmark$ & $\checkmark$ & & $\checkmark$ & \\
\hline $\begin{array}{l}\text { Interface amigável e estrutura } \\
\text { de fácil uso }\end{array}$ & $y$ & $\checkmark$ & 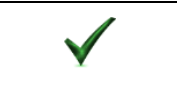 & $\checkmark$ & \\
\hline $\begin{array}{l}\text { Realizar o acompanhamento do } \\
\text { progresso do aluno }\end{array}$ & $x$ & $x$ & $x$ & $x$ & \\
\hline $\begin{array}{l}\text { Fornecer meios/canais para } \\
\text { comunicação/ discussão entre } \\
\text { os usuários }\end{array}$ & $x$ & * & $\checkmark$ & $x$ & \\
\hline Utilizar gamification & $\checkmark$ & $\checkmark$ & $\checkmark$ & $\checkmark$ & $V$ \\
\hline $\begin{array}{l}\text { Utilizar personalização da } \\
\text { Aprendizagem }\end{array}$ & $x$ & $x$ & $x$ & $x$ & 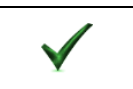 \\
\hline
\end{tabular}

A ferramenta possui dois tipos de perfis: o do aluno e do professor. No perfil do aluno, o estudante pode escolher um quiz para responder, acessar o material da disciplina, verificar o ranking e verificar as mensagens enviadas pelo professor. Quando o professor adiciona um novo quiz no ambiente, os estudantes recebem um e-mail para informá-los. Cada notificação apresenta um MEME diferente, objetivando tornar a notificação divertida. As perguntas do quiz respondidas corretamente geram uma pontuação incremental. O estudante tem apenas uma chance para responder às perguntas do quiz, no entanto se errar não perde ponto. Na tela (Figura 2), para responder o quiz, há um botão chamado "Compile Now". Ao clicar nesse botão, o aluno acessará outra janela ativando um compilador online, da linguagem que ele está aprendendo. Este recurso permite que o aluno compile o código quando considerar relevante para responder uma questão, e, o sistema exibe se o estudante acertou ou não. Ao finalizar o quiz o estudante pode ver todas as respostas deste.

Para o perfil do professor, o cod[edu]disponibiliza as funções de criar disciplinas, adicionar material da aula, criar quiz, enviar mensagens para os estudantes e um relatório geral da turma e de cada aluno que responderem os quizzes. Nesse contexto, o professor pode verificar quais as possíveis dúvidas dos alunos e suas deficiências, possibilitando revisar o assunto de acordo com essas informações. $\mathrm{O}$ docente pode ainda analisar o desempenho de cada aluno pelos assuntos do quiz observando a quantidade de acertos e erros por estudante através de gráficos interativos que ao passar o mouse, o docente pode visualizar os nomes dos estudantes. 


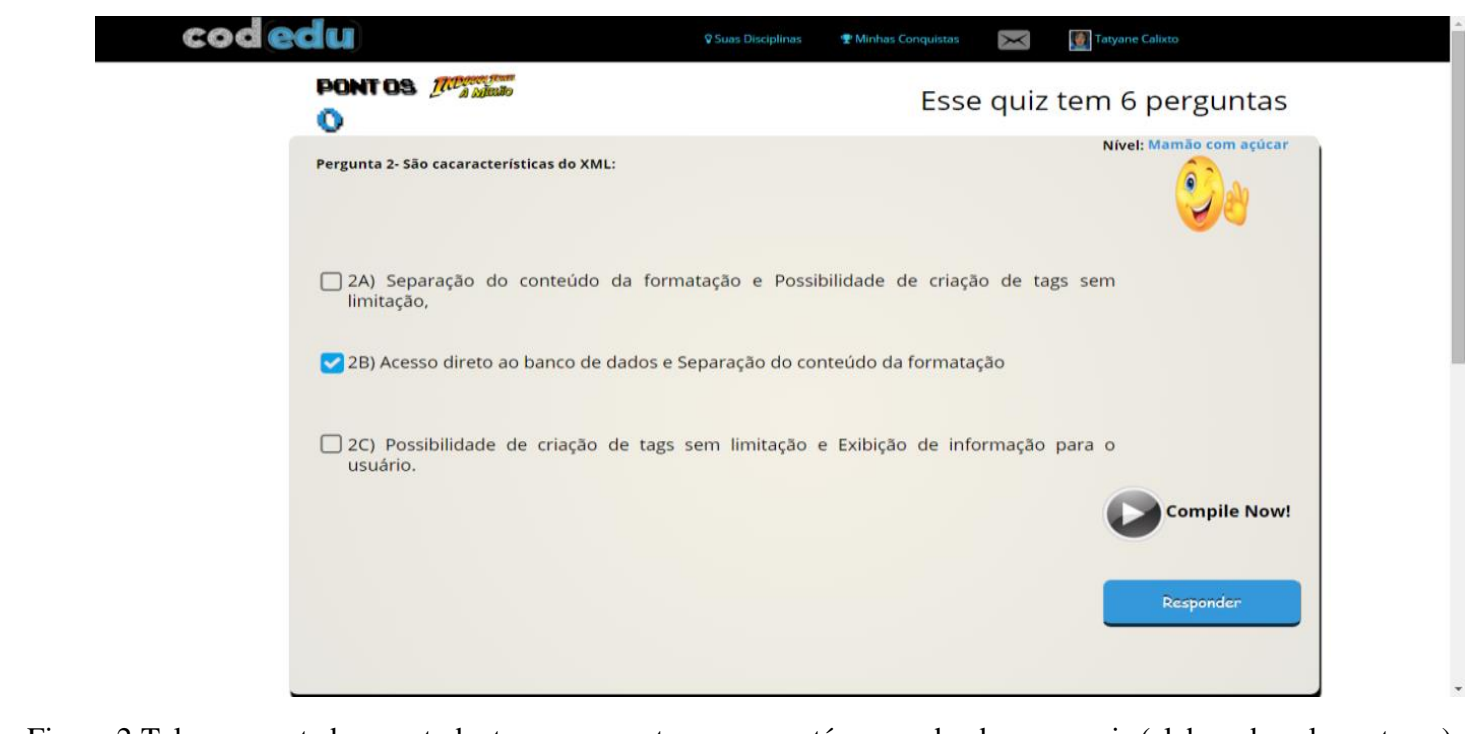

Figura 2:Tela apresentada ao estudante no momento em que está respondendo a um quis (elaborada pelas autoras).

\section{Estudo Experimental}

O modelo conceitual cod[edu] foi implementado e aplicado com estudantes do ensino superior. O quase-experimento é descrito a seguir.

\subsection{Contexto da Pesquisa e Participantes}

O presente estudo foi realizado com quatro turmas, sendo três turmas do segundo, terceiro e sétimo períodos da FACOL (Faculdade Escritor Osman da Costa Lins) nas disciplinas de Linguagem de Definição de Dados XML, Programação Orientada a Objetos e PHP respectivamente, do curso de Sistemas de Informação, ministradas pelo mesmo professor da referida faculdade. Além destas, uma turma da disciplina de Programação Orientada a Objeto da UFRPE (Universidade Federal Rural de Pernambuco) do terceiro período do curso de Licenciatura em Computação. A pesquisa foi realizada no período de 19 de setembro a 30 de Novembro de 2015.

A população do grupo experimental foi composta por vinte e quatro alunos, no qual 7 estudantes foram da disciplina de PHP, 14 de Linguagem de Definição de Dados XML da FACOL e 3 da disciplina de Programação Orientada a Objeto da UFRPE.

O grupo de controle foi formado por sete alunos da disciplina de Programação Orientada a Objetos (POO) da FACOL. A atribuição dos participantes do grupo de controle e experimental foi realizada de forma aleatória. Sendo assim, um quase-experimento foi realizado, pois é adequado para o contexto educacional em virtude das questões éticas envolvidas (Shadish, Cook, \& Campbell, 2002).

A intervenção com a ferramenta foi realizada de forma separada para cada turma, pois os assuntos das disciplinas eram distintos.

\subsection{Pergunta de Pesquisa}

Os subtópicos a seguir apresentam a pergunta de pesquisa e as hipóteses que foram formuladas para respondê-la.

\subsubsection{Pergunta de Pesquisa 1:}

- Há influência positiva de gamification no engajamento e desempenho dos estudantes no aprendizado de programação? 


\subsubsection{Hipótese de Nulidade (HO)}

- Pergunta de Pesquisa 1:

o A personalização do aprendizado em programação, através do uso de gamification e contexto, não colabora para o engajamento estudantil.

\subsubsection{Hipótese Alternativa (Ha)}

- Pergunta de Pesquisa 1:

o A personalização do aprendizado em programação, através do uso de gamification e contexto, colabora para o engajamento estudantil.

\subsection{Coleta de Dados e Execução}

O primeiro estágio da coleta de dados contemplou a aplicação de um questionário com intuito de conhecer e mensurar os indicadores de engajamento dos estudantes antes da utilização da ferramenta cod[edu].

O questionário dos indicadores de engajamento estudantil possui nove questões (https://goo.gl/kePSiJ). Cada pergunta aborda um indicador, sendo distribuídos da seguinte forma: Autonomia, Execução, Social, Entrega, Participação, Colaboração, Cooperação, Questionamento e Diversão. Para responder as perguntas, os alunos utilizaram a escala de Likert com os seguintes itens: Discordo Totalmente (DT), Discordo parcialmente (DP), Indiferente (I), Concordo parcialmente (CP) e Concordo totalmente (CT) (Likert, 1932). O resultado do questionário dos indicadores de engajamento pode ser visualizado na Figura 3 e Figura 4.

Para a confiabilidade do questionário foi utilizado o coeficiente de Alfa de Cronbach (Cronbach, 1951). O cálculo de Alfa de Crombach do questionário pré-teste dos indicadores de engajamento resultou em 0,72 , podendo ser classificado como consistente.

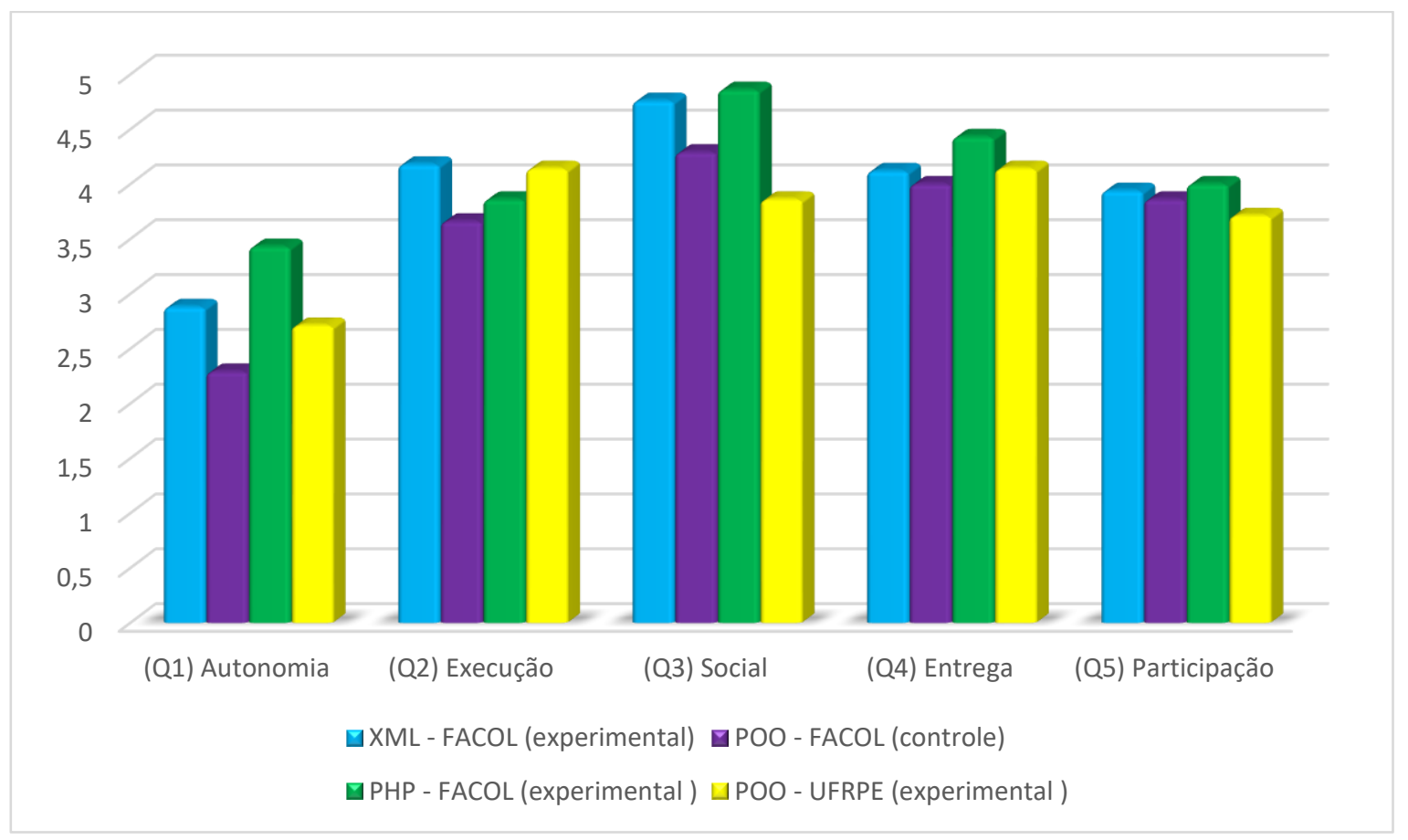

Figura 3: Indicadores de engajamento de todas as turmas (elaborado pelas autoras). 


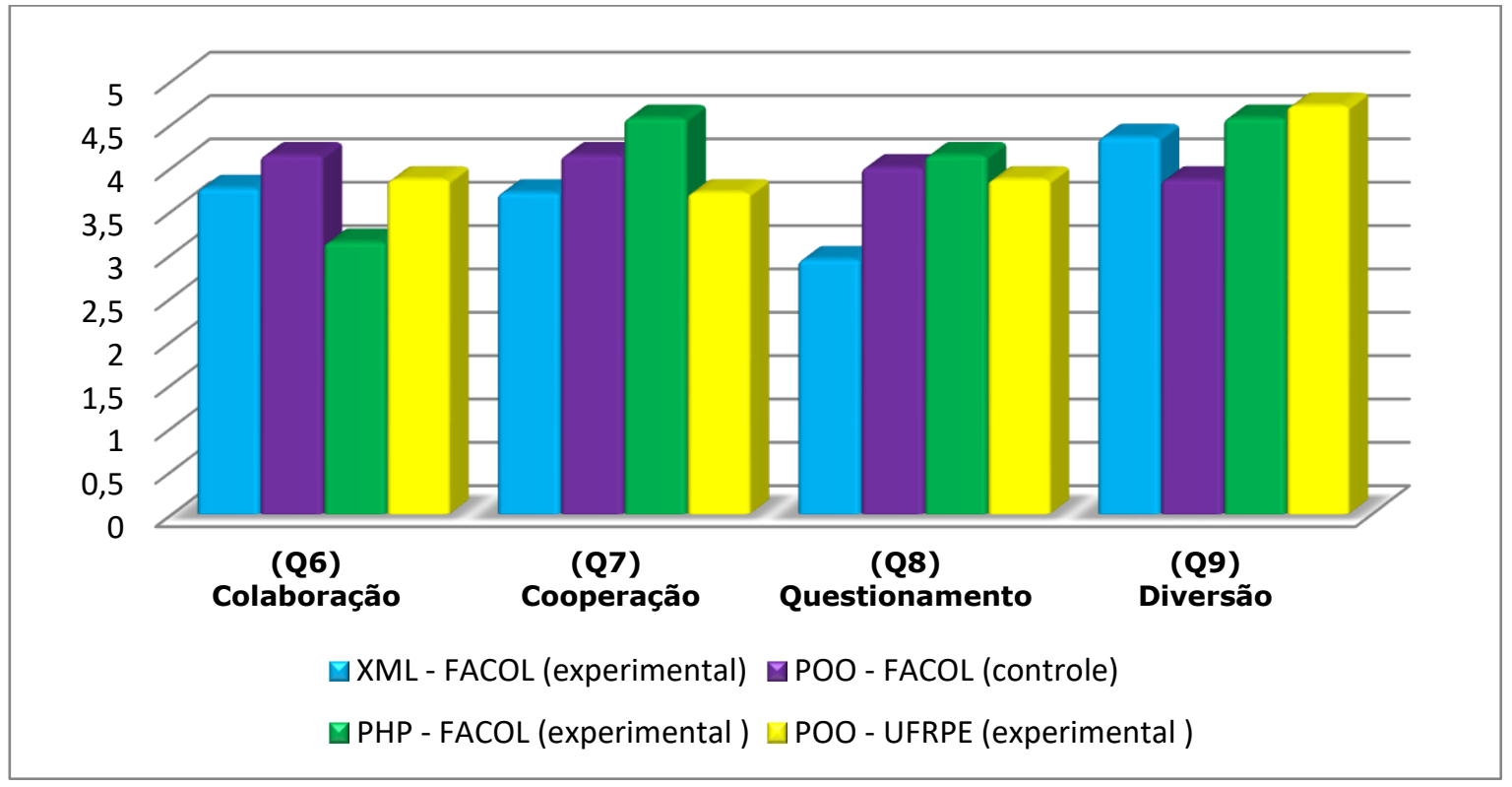

Figura 4: Indicadores de engajamento de todas as turmas (elaborado pelas autoras).

Uma vez realizada a intervenção com a ferramenta e com a finalidade de saber se os indicadores de engajamento dos alunos foram alterados após a utilização do cod[edu], foi aplicado um questionário que abordou os mesmos elementos do questionário utilizado no préteste, no qual os estudantes responderam usando também a escala de Likert (Likert, 1932). Para esse questionário (link: https://goo.gl/DFy2xC) também foi realizado o cálculo de Alfa de Crombach (Cronbach, 1951) que obteve o resultado de 0,86 . O resultado do pós-teste dos indicadores de engajamento podem ser visualizados nas Figuras 5, 6 e 7.

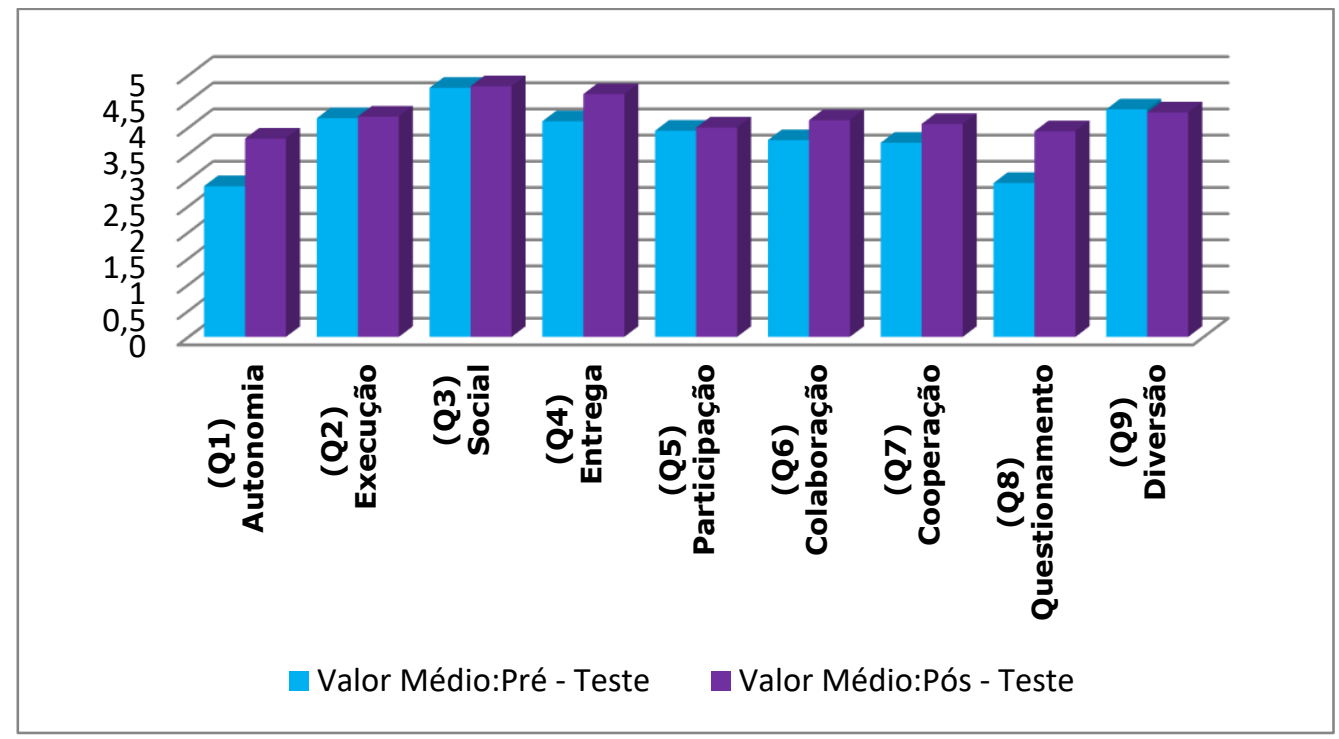

Figura 5: Valor médio das Respostas da Turma de XML - FACOL - Indicadores de Engajamento (elaborado pelas autoras). 


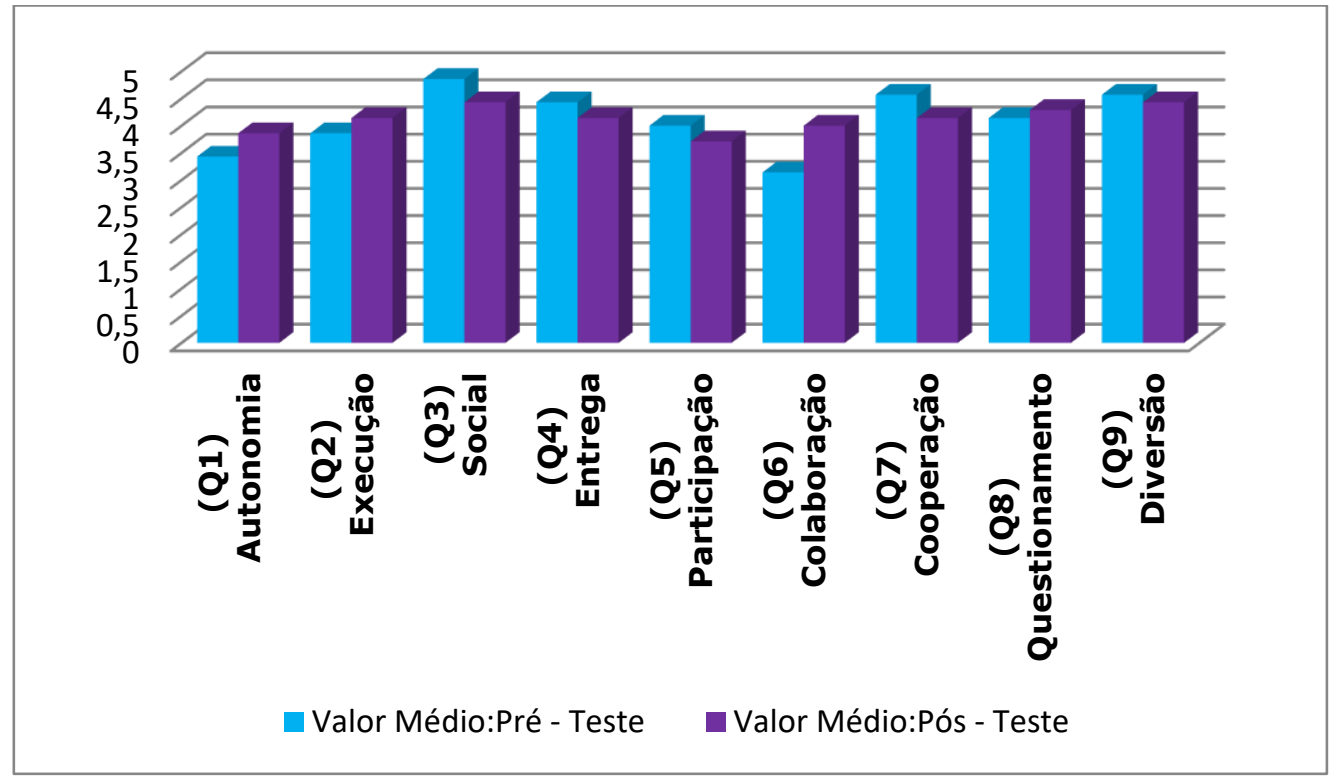

Figura 6 :Valor médio das respostas da turma de PHP - FACOL - indicadores de engajamento (elaborado pelas autoras).

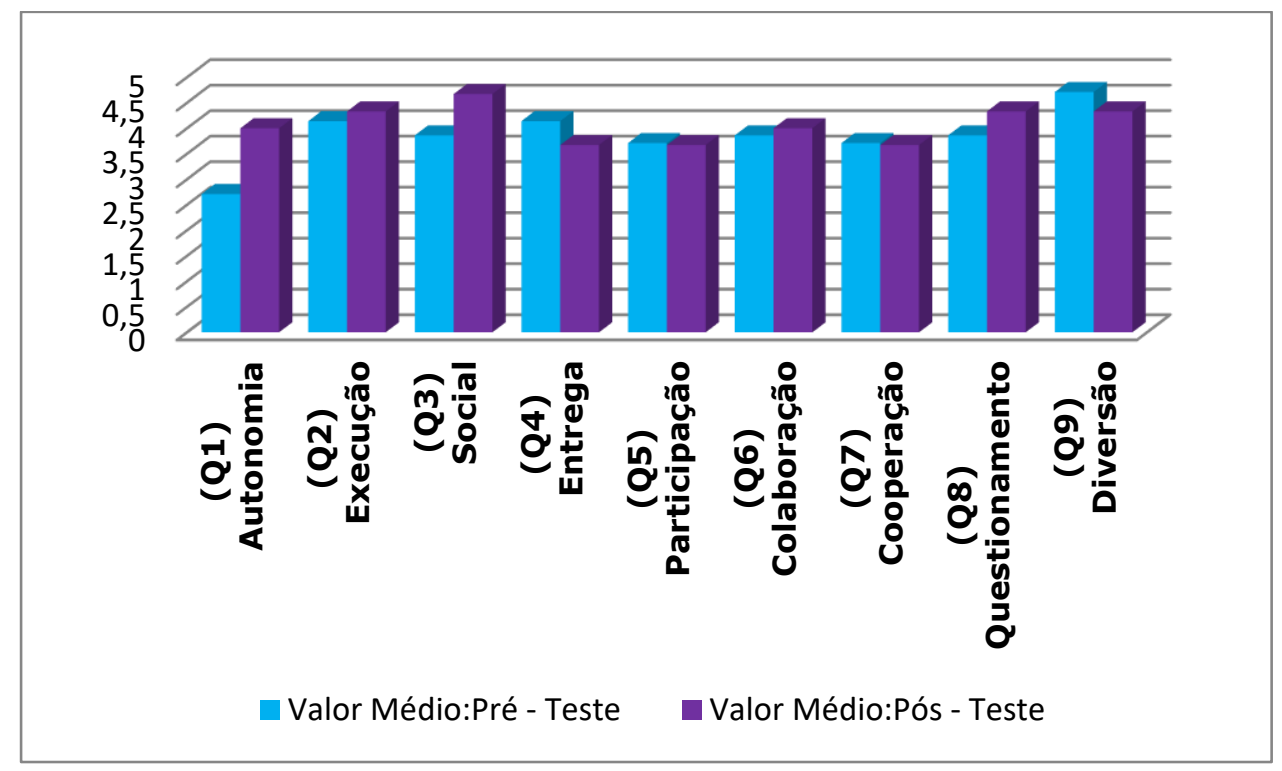

Figura 7: Valor médio das respostas da turma de programação - UFRPE - indicadores de engajamento (elaborado pelas autoras).

\subsection{Discussão}

$\mathrm{Na}$ seção anterior do presente trabalho foi apresentado o ambiente cod[edu], sua utilização em turmas de programação, bem como os resultados alcançados com o estudo experimental que avaliou o modelo do ambiente em um cenário de aprendizagem.

O experimento realizado foi conduzido por uma questão de pesquisa que pretendeu constatar a influência positiva da utilização do cod[edu] no engajamento e desempenho dos estudantes no processo de aprendizagem de programação, no qual obteve resultados significativos.

No que se refere aos indicadores de engajamento: Autonomia, Execução, Entrega, Participação, Questionamento e Diversão, exceto Social, Colaboração e Cooperação que não foram contemplados pelas funcionalidades do $\operatorname{cod}[\mathrm{edu}]$, a maioria dos indicadores apresentou mudança positivas após a intervenção didática com o modelo (Quadro 1). Tal resultado pode 
estar relacionado com a utilização de gamification no cod[edu] tendo como finalidade a promoção do engajamento de estudantes nas atividades. $O$ indicador de engajamento Autonomia, por sua vez, apresentou mais variações e aumento no valor médio observado nas três turmas. Isso pode estar atrelado à evolução dos estudantes ao utilizar o cod[edu], os quais se sentiam competentes, ao responderem o quiz e ao visualizar seu crescimento no ranking.

Em relação ao indicador Execução houve um aumento observado nas três turmas, isso pode ser relacionado com a característica do indicador que é percebido quando o estudante está no controle de suas atividades de aprendizagem e o cod[edu]proporcionou isso, pois os estudantes podiam responder o quiz, mesmo em sala, consultando ou tirando dúvidas com o professor.

Em relação à Entrega e Participação houve uma diminuição nos valores médios, embora existam funcionalidades no sistema que contemplam esses indicadores, houve uma diminuição em duas das três turmas, no entanto, as afirmações continuaram na mesma escala de afirmações positivas.

Quadro 1: Relação entre as funcionalidades do cod[edu]e o indicadores de engajamento estudantil (elaborado pelas autoras).

\begin{tabular}{|l|l|}
\hline $\begin{array}{c}\text { INDICADORES DE } \\
\text { ENGAJAMENTO } \\
\text { ESTUDANTIL }\end{array}$ & \multicolumn{1}{|c|}{ FUNCIONALIDADES DO COD[EDU] } \\
\hline$(Q 1)$ Autonomia & $\begin{array}{l}\text { Promove Autonomia dos estudantes, uma vez que possibilita flexibilidade de } \\
\text { responder o quiz a qualquer momento e em qualquer lugar sem a intervenção do } \\
\text { Professor. }\end{array}$ \\
\hline$(Q 2)$ Execução & $\begin{array}{l}\text { O docente tem a possibilidade de solicitar que os alunos respondam o quiz em } \\
\text { sala de aula. }\end{array}$ \\
\hline$(Q 3)$ Social & O code[edu] não contempla esse item. \\
\hline$(Q 4)$ Entrega & $\begin{array}{l}\text { O professor pode requisitar que os estudantes respondam o quiz em um dia } \\
\text { específico e verificar o resultado através do gráfico gerado pelo sistema. }\end{array}$ \\
\hline$(Q 5)$ Participação & O cod[edu]não contempla esse item. \\
\hline$(Q 6)$ Colaboração & O cod[edu]não contempla esses itens. \\
\hline$(Q 7)$ Cooperação & $\begin{array}{l}\text { Quando uma questão do quiz produz dúvida no aluno, esse pode levar o } \\
\text { questionamento para sala de aula. Pois, o feedback é rápido após responder as } \\
\text { perguntas. }\end{array}$ \\
\hline $\begin{array}{l}(Q 8) \\
\text { Questionamento }\end{array}$ & $\begin{array}{l}\text { A ferramenta possui elementos de jogos e pode contribuir com a diversão } \\
\text { através de: pontuação, ranking, competição, narrativa, progress bar e badges. }\end{array}$ \\
\hline$(Q 9)$ Diversão
\end{tabular}

No que concerne ao indicador Questionamento houve um aumento significativo nas três turmas, inclusive mudando de escala, em duas turmas, para afirmações positivas de "Concordo Parcialmente". Tais elementos mostram que o modelo cod[edu]influenciou positivamente para que o ambiente se mostrasse propício para questionamentos.

O indicador de engajamento Diversão apresentou uma diminuição no valor médio, permanecendo, no entanto, na mesma escala de afirmação de "Concordo Parcialmente", sugerindo que a intervenção com o cod[edu]propiciou aos estudantes um estado de intensa concentração e envolvimento no cumprimento da tarefa, pois houve satisfação ao realizá-la, uma vez que os mesmos a consideraram divertida.

No que concerne a avaliação do modelo conceitual do cod[edu], observou-se que os estudantes mais engajados no sistema tinham o perfil de jogador em acordo com aqueles classificados pelo cod[edu]. Com isso, podemos inferir que a personalização das técnicas de engajamento, baseadas no perfil de jogador e adicionadas no sistema através dos elementos de jogos, influenciaram de forma positiva o engajamento dos discentes. 
Diante do desempenho dos estudantes, considerando os objetivos educacionais, classificando as questões do quiz segundo a taxonomia de Bloom, pode-se perceber que os estudantes da turma da disciplina de XML da FACOL, apresentaram um ótimo desempenho nas perguntas classificadas na categoria Lembrar, tendo em vista o alto índice nos indicadores de engajamento. Essa análise foi embasada também no modelo conceitual, visto que essa categoria está relacionada com as técnicas de engajamento que proporcionam recompensas ao realizar uma atividade. As turmas de PHP da FACOL e POO da UFRPE apresentaram um bom desempenho em vários níveis de abstração da taxonomia de Bloom. A turma de POO da UFRPE obteve o melhor desempenho, podendo ser um reflexo dos indicadores de engajamento que foram maiores para esta turma, mostrando que as técnicas de engajamento atreladas aos objetivos educacionais apresentaram resultados positivos. Sendo assim, é possível inferir que há influência positiva na utilização gamification, técnicas de engajamento para alcançar os objetivos educacionais exigidos para aprender programação.

Com intuito de ter uma visão mais completa sobre os resultados obtidos com o quaseexperimento, foi realizada uma entrevista estruturada com os professores do grupo experimental. A avaliação do cod[edu]feita pelos professores foi positiva, uma vez que afirmaram que o modelo proposto auxilia no engajamento dos estudantes, ajudando também no processo de aprendizagem dos alunos na disciplina de programação.

\section{Conclusão}

A disciplina de programação é essencial na formação do discente de Computação uma vez que as habilidades adquiridas na sua aprendizagem corroboram para a resolução de problemas reais. Entretanto, os obstáculos encontrados para desenvolver o raciocínio lógico matemático, analisar e elaborar soluções para resolver os problemas algoritmicamente podem interferir no aperfeiçoamento dessa habilidade. Tais dificuldades são a grande causa, segundo Martins e Correia (2003), de reprovação, desmotivação e desistência dos estudantes nos cursos de Computação.

Diante desse quadro, promover o engajamento estudantil durante o período de ensino e aprendizagem de programação é um desafio que pode ser superado com a utilização de técnicas de engajamento, de gamification e aprendizagem contextualizada.

$\mathrm{O}$ ambiente de aprendizagem cod[edu] descrito, implementado e testado durante a pesquisa aqui reportada, tem a finalidade de amenizar esse problema, através de funcionalidades que permitem ao docente acompanhar e fornecer o feedback das atividades rapidamente, além de ajudar a promover e manter o engajamento do estudante durante o seu processo de aprendizagem.

\subsection{Contribuições da Pesquisa}

Considerando a perspectiva do ensino de programação a pesquisa contribuiu para o engajamento dos estudantes durante o processo de aprendizagem dessa disciplina, dentre as quais podemos citar: criação e avaliação de um modelo conceitual para a promoção do engajamento dos estudantes com intuito de auxiliar, o processo de ensino-aprendizagem de alunos em programação a nível superior. A pesquisa contemplou ainda o estudo experimental realizado com discentes das disciplinas de programação envolvidas no procedimento, onde se pode verificar a influência do modelo proposto no aprendizado dos estudantes, confirmada através dos indicadores de engajamento. Além do favorecimento do envolvimento do estudante durante o processo de aprendizagem de programação, uma vez que o modelo conceitual do cod[edu] aborda uma grande parte dos indicadores de engajamento em sua funcionalidade. $\mathrm{O}$ estudo abordou o ensino personalizado, usando o perfil dos jogadores para promover o engajamento 
estudantil, por intermédio de elementos de games e o favorecimento do acompanhamento do desempenho dos estudantes, pelo professor, de forma rápida e dinâmica.

As contribuições são reafirmadas pelos resultados ao usar o modelo, por intermédio da ferramenta cod[edu], mensurados através dos indicadores de engajamento estudantil, uma vez que, os valores desses parâmetros aumentaram após a utilização do ambiente cod[edu]. Embora os estudos tenham se voltado para auxiliar a aprendizagem de programação, o modelo proposto no presente trabalho foi desenvolvido de modo a poder ser utilizado em outras disciplinas, mediante pequenos ajustes.

\subsection{Limitações}

As limitações desta pesquisa serão apresentadas a seguir: a elaboração dos questionários com objetivo de conhecer os indicadores de engajamento dos estudantes antes e depois da utilização do ambiente de aprendizagem pode ter sido enviesada. É possível ainda que os sujeitos possam ficar mais engajados ou não com o passar do tempo, sendo esse comportamento diferente do analisado no questionário já citado.

A escolha dos estudantes que participaram da pesquisa ocorreu de forma não aleatória. No que se refere ao quase-experimento pode-se destacar o pequeno número de interações e participantes. Nesse projeto, não foi possível evitar essa peculiaridade para essa pesquisa.

No que concerne ao sistema de recomendação baseada em conteúdo, uma limitação está relacionada à criação do perfil do usuário, pois é necessário avaliar um número suficiente de itens, a fim de que as recomendações sejam mais precisas e relevantes. Sendo assim, um usuário novo, que tem poucas avaliações e interações, não terá recomendações muito precisas ou pode não haver recomendação. No estudo, esta situação ocorreu através do percentual de usuários que não tiveram seu perfil de jogador classificado pelo sistema.

A classificação das perguntas segundo a Taxonomia de Bloom ser realizada por apenas uma pesquisadora. As avaliações dos resultados dos indicadores de engajamento dos estudantes os quais foram realizados por apenas uma pesquisadora.

\subsection{Trabalhos Futuros}

A presente pesquisa cumpriu os objetivos traçados e obteve êxito ao utilizar gamification como estratégia no engajamento de estudantes para auxiliar o aprendizado de programação. Os resultados obtidos conduziram a possíveis trabalhos futuros, descritos a seguir: mapear os períodos de maior e menor engajamento estudantil ao longo do processo de aprendizagem do discente; utilizar o modelo para auxiliar o engajamento de estudantes em outras disciplina, uma vez que o modelo foi desenvolvido de modo a ser aplicado em qualquer disciplina, necessitando, para isto, apenas a contextualização dos badges; ampliar o modelo para que este possa abranger várias disciplinas, podendo o usuário selecionar os badges de acordo com a matéria a ser ensinada, uma vez aplicado a outras disciplinas; verificar se as técnicas de engajamento se adéquam a estas, comparando as avaliações do modelo com aquelas realizadas para o ensino de programação; replicar o experimento realizado em outras turmas de programação para alunos no início do curso, com um número maior de interações e participantes; adicionar a funcionalidade de balanceamento do nível das questões do quiz, levando em consideração os acertos e erros dos estudantes; adicionar a funcionalidade de exercícios práticos sugerida pelos professores que utilizaram a ferramenta; adicionar a funcionalidade que possibilite o envio de exercícios pelos alunos e pontuação atribuída apenas após a avaliação do professor, sugestão dada por um dos docentes.

\section{Agradecimentos}


Os autores agradecem ao Conselho Nacional de Desenvolvimento Científico e Tecnológico $(\mathrm{CNPq})$ pelo financiamento desta pesquisa.

\section{Referências}

Alves, F. (2014). Gamification: como criar experiências de aprendizagem engajadoras. DVS Editora.[GS Search]

Atweh, B., Bland, D. C., Carrington, S. B., \& Cavanagh, R. (2008). School disengagement: Its constructions, investigation and management. Disponível em: http://eprints.qut.edu.au/17737/1/c17737.pdf. [GS Search]

Bartle, R. (1996). Hearts, clubs, diamonds, spades: Players who suit MUDs. Journal of MUD research, 1(1), 19. [GS Search]

Bloom, B. S. (1956). Taxonomy of educational objectives: The classification of educational goals: Cognitive Domain. Longman. [GS Search]

Brazil, A., \& Baruque, L. (2015, October). Gamificação Aplicada na Graduação em Jogos Digitais. In Brazilian Symposium on Computers in Education (Simpósio Brasileiro de Informática na Educação-SBIE) (Vol. 26, No. 1, p. 677). doi: 10.5753/cbie.sbie.2015.677. Disponível em: http://www.br-ie.org/pub/index.php/sbie/article/view/5338. [GS Search]

Brito, A., \& Madeira, C. (2015, October). XP \& Skills: gamificando o processo de ensino de introdução a programação. In Anais dos Workshops do Congresso Brasileiro de Informática na Educação (Vol. 4, No. 1, p. 1124). doi: 10.5753/cbie.wcbie.2015.1124. Disponível em: http://br-ie.org/pub/index.php/wcbie/article/viewFile/6235/4360. [GS Search]

Codecademy (2015, april). Disponível em: https://www.codecademy.com/pt.

Code School (2015, april). Disponível em: https://www.codeschool.com/.

Costa, M.M., \& Giraffa, L. M. M. (2013). Evasão na Disciplina de Algoritmo e Programação: um Estudo a partir dos Fatores Intervenientes na Perspectiva do Aluno. In Tercera Conferencia sobre el Abandono en la Educación Superior (III CLABES, 2013, Espanha). [GS Search]

Cronbach, L. J. (1951). Coefficient alpha and the internal structure of tests. psychometrika, 16(3), 297-334. [GS Search]

Deterding, S., Dixon, D., Khaled, R., \& Nacke, L. (2011, September). From game design elements to gamefulness: defining gamification. In Proceedings of the 15th international academic MindTrek conference: Envisioning future media environments (pp. 9-15). ACM. doi: $\underline{10.1145 / 2181037.2181040}$. [GS Search]

Fredricks, J. A., Blumenfeld, P. C., \& Paris, A. H. (2004). School engagement: Potential of the concept, state of the evidence. Review of educational research,74(1), 59-109. doi: 10.3102/00346543074001059. [GS Search]

Ghozland, D. (2010, April). Designing for Motivation. Gamasutra. Disponível em: http://www.gamasutra.com/

Giraffa, L., Muller, L., \& Moraes, M. C. (2015). Ensinado Programação apoiada por um ambiente virtual e exercícios associados a cotidiano dos alunos: compartilhando alternativas e lições aprendidas. In Anais dos Workshops do Congresso Brasileiro de Informática na Educação (Vol. 4, No. 1, p. 1330). doi: 10.5753/cbie.wcbie.2015.1330. Disponível em: http://br-ie.org/pub/index.php/wcbie/article/viewFile/6303/4412. [GS Search] 
Gomes, A., \& Mendes, A. (2014). A teacher's view about introductory programming teaching and learning: Difficulties, strategies and motivations. In Frontiers in Education Conference (FIE), 2014 IEEE (pp. 1-8). IEEE. doi: 10.1109/FIE.2014.7044086. [GS Search]

INEP.(2012).Instituto Nacional de Estudos e Pesquisas Educacionais Anísio Teixeira. Disponível em: http://portal.inep.gov.br/

de Jesus, E. A., \& Raabe, A. L. A. (2009). Interpretações da Taxonomia de Bloom no Contexto da Programação Introdutória. In Brazilian Symposium on Computers in Education (Simpósio Brasileiro de Informática na Educação-SBIE) (Vol. 1, No. 1). Disponível em: http://www.br-ie.org/pub/index.php/sbie/article/viewFile/1151/1054. [GS Search]

Kapp, K. M. (2012). Games, gamification, and the quest for learner engagement. $T+D, 66(6), 64-$ 68. [GS Search]

Lahtinen, E., Ala-Mutka, K., \& Järvinen, H. M. (2005). A study of the difficulties of novice programmers. In Acm Sigcse Bulletin (Vol. 37, No. 3, pp. 14-18). ACM. doi: 10.1145/1067445.1067453. [GS Search]

Li, C., Dong, Z., Untch, R., Chasteen, M., \& Reale, N. (2011). Peerspace-an online collaborative learning environment for computer science students. In Advanced Learning Technologies (ICALT), 2011 11th IEEE International Conference on (pp. 409-411). IEEE. doi: 10.1109/ICALT.2011.129. [GS Search]

Likert, R. (1932). A technique for the measurement of attitudes. Archives of psychology.[GS Search]

Martins, S. W., \& Correia, L. H. D. A. (2003). O Logo como ferramenta auxiliar no desenvolvimento do raciocínio lógico-um estudo de caso. In Internacional Conference on Engineering and Computer Education-ICECE. [GS Search]

Pádua, W. P. (2001). Engenharia de Software - Fundamentos, Métodos e Padrões. [GS Search]

Parsons, J., \& Taylor, L. (2011). Improving student engagement. Current issues in education, 14(1). [GS Search]

Peixoto, M., Silva, C., Vilela, J., \& Gonçalves, E. (2015). Um mapeamento sistemático de gamificação em software educativo no contexto da comunidade brasileira de informática na educação. In Anais do Workshop de Informática na Escola (Vol. 21, No. 1, p. 584). doi: 10.5753/cbie.wie.2015.584. Disponível em: $\underline{\text { http://br- }}$ ie.org/pub/index.php/wie/article/download/5104/3509. [GS Search]

Russell, B., \& Slater, G. (2010). Factors that encourage student engagement: Insights from a case study of "first time" students in a New Zealand university. Journal of University Teaching \& Learning Practice, 8(1). [GS Search]

SBC (1999) - Sociedade Brasileira de Computação. Currículo de Referência da SBC para Cursos de Graduação em Computação e informática. [GS Search]

Scott, T. (2003). Bloom's taxonomy applied to testing in computer science classes. Journal of Computing Sciences in Colleges, 19(1), 267-274. [GS Search]

Seixas, L., de Melo Filho, I. J., \& Gomes, A. S. (2015). Identifying engagement indicators to support educational research. In Information Systems and Technologies (CISTI), 2015 10th Iberian Conference on (pp. 1-6). IEEE. doi: 10.1109/CISTI.2015.7170357. [GS Search]

Sena, A., \& Coelho, D. K. (2012). Motivação dos Jogadores de Videogame-Uma breve visão sobre as Técnicas de Engajamento. XI SBGAMES. Disponível em: http://www.sbgames.org/sbgames2012/proceedings/papers/cultura/C_S4.pdf . [GS Search] 
Shadish, W. R., Cook, T. D., \& Campbell, D. T. (2002). Experimental and quasi-experimental designs for generalized causal inference. Wadsworth Cengage learning. [GS Search]

Swacha, J., \& Baszuro, P. (2013). Gamification-based e-learning platform for computer programming education. In X World Conference on Computers in Education (pp. 122-130). [GS Search]

Tarallo, F. B., Rozenfeld, H., \& Barbalho, S. C. M. (2003). E-learning: um estudo de requisitos e best practices tecnológicas. [GS Search]

Vianna, Y., Vianna, M., Medina, B., \& Tanaka, S. (2013). Gamification, Inc: como reinventar empresas a partir de jogos. Rio de Janeiro: $M J V$.

Vieira, F. J. R.; Nunes, M. A. S. N. DICA: Sistema de Recomendação de Objetos de Aprendizagem Baseado em Conteúdo. Scientia Plena, v. 8, n. 5, 2012. [GS Search]

Vieira, V., Tedesco, P., \& Salgado, A. C. (2009). Modelos e Processos para o desenvolvimento de Sistemas Sensíveis ao Contexto. André Ponce de Leon F. de Carvalho, Tomasz Kowaltowski.(Org.). Jornadas de Atualização em Informática, 381-431. [GS Search]

Viter, L.N. (2013). Interação e Engajamento em Ambiente Virtual de Aprendizagem: um estudo de caso. [GS Search]

Whalley, J. L., Lister, R., Thompson, E., Clear, T., Robbins, P., Kumar, P. K., \& Prasad, C. (2006). An Australasian study of reading and comprehension skills in novice programmers, using the bloom and SOLO taxonomies. In Proceedings of the 8th Australasian Conference on Computing Education-Volume 52 (pp. 243-252). Australian Computer Society, Inc. ISBN:1-920682-34-1 [GS Search]

Yang, T. C., Yang, S. J., \& Hwang, G. J. (2014). Development of an interactive test system for students' improving learning outcomes in a computer programming course. In Advanced Learning Technologies (ICALT), 2014 IEEE 14th International Conference on (pp. 637639). IEEE. doi: 10.1109/ICALT.2014.186. [GS Search]

Zichermann, G., \& Cunningham, C. (2011). Gamification by design: Implementing game mechanics in web and mobile apps. " O'Reilly Media, Inc. [GS Search] 